\title{
A new approach to the mathematical model of thermal energy balance
}

\author{
Elena Kitaytseva* \\ Moscow State University of Civil Engineering, Yaroslavskoe shosse, 26, Moscow, 129337, Russia
}

\begin{abstract}
Formation of balance of thermal energy and the heat carrier for a thermal network is carried out for the purpose of increase of efficiency of work of the heat supplying organization. The standard approach proposes to write off the difference between the released and realized heat energy for heat losses. The article proposes a new approach to the formation of the balance of thermal energy and coolant. It includes statistical analysis of telemetry data relating to the released thermal energy. Heat consumption was estimated by contractual load for heating, ventilation and hot water supply. In the mathematical model of the thermal balance for each term weight coefficients were introduced. To obtain the numerical values of these coefficients, the method of least squares was used. The results of checking the adequacy of mathematical models that take into account or neglect thermal losses are presented. The obtained coefficients for the mathematical model of heat balance were used for the mathematical model of mass balance. The results can be used to predict the cost of production and transmission of heat energy and coolant, to assess the efficiency of the heat network and the formation of tariff applications for the future.
\end{abstract}

\section{Introduction}

The heat pipelines as others engineering systems are a part of every human settlement. If the city turns into a Smart city, then engineering systems must be satisfied to the status Smart Grid. There are no opponents of the necessity of development and introduction of ideas, which increase "the intellectuality" of heat pipelines. The process of engineering systems turning into the other intellectual level can be rather long.

\section{Literature review}

Pumping stations, subscriber inputs, heat supply sources are accepted to equip by the means of automatic and telementry [1]. The identification of necessary and sufficient amount of the intervening establishments, which are equipped by the telemetrical means, and their territorial disposition merit a special research. In general present publications [2-11] observe problems related with complete automation of data on energy consumption

\footnotetext{
* Corresponding author: keh2@bk.ru
} 
collection and transfer. There is practically no discussion of issues related to the processing and analysis of the collected information, the Range of tasks that can be solved with new approaches to the automation of information collection from all objects of the network will expand.

One of the aim is a aim of preparation of heat and material balance of the network. One of these tasks is the task of drawing up the thermal and material balance of the network. To solve this problem, it is necessary to collect synchronized information from the sources supplying the network and from the consumers connected to the network. The full amount of data will allow to estimate the heat losses and leaks that occur during the transport of the coolant. The time period for which the balance is drawn is determined by the frequency of obtaining the initial information.

\section{Methods}

The mathematical model of heat balance is based on the law of heat energy conservation:

$$
Q=Q_{H V}+Q_{H W}+Q_{H L},
$$

Where Q, Gcal/day - is the amount of thermal energy released into the network;

$Q_{H V}=\sum_{j=1}^{k_{1}} Q_{H V}, \mathrm{Gcal} / \mathrm{day}$, - consumed energy by all heating and ventilation systems;

$\mathrm{k}_{1}$ - number of subscribers with heating and ventilation systems;

$Q_{2}=\sum_{j=1}^{k_{2}} Q_{H W_{j}}$, Gcal/day, - energy consumed by all hot water supply systems;

$\mathrm{k}_{2}$ - number of subscribers with hot water supply systems;

$Q_{H L}, \mathrm{Gcal} / \mathrm{day}$, heat losses through thermal insulation of pipelines and equipment.

Consider ways to obtain information about each component of the balance (1).

The amount of energy released $\mathrm{Q}$ is determined by the formula using the measurement results:

$$
Q=\sum_{i=1}^{k} Q_{i}=\sum_{i=1}^{k} c\left(G_{S i} \cdot t_{S i}-G_{r_{i}} \cdot t_{r_{i}}\right)
$$

Where $\mathrm{c}, \mathrm{Gcal} /\left(\mathrm{t}{ }^{\circ} \mathrm{C}\right)$ - the heat capacity of water;

$G_{s_{i}}, \mathrm{t} / \mathrm{day}$, - coolant flow rate in the i supply pipeline;

$t_{s_{i}}{ }^{\circ} \mathrm{C}$, - coolant temperature at the inlet of the i supply pipeline;

$G_{r_{i}}, \mathrm{t} /$ day, - coolant flow rate in the I-th return pipeline;

$t_{r_{i}}{ }^{\circ} \mathrm{C}$, - coolant temperature at the outlet of the i return pipeline.

The number of terms in the formula (2) is determined by the number of working pipes $\mathrm{k}$.

The energy consumed by heating, ventilation and hot water systems can be estimated from the data of consumer metering units. This requires not only the presence of these nodes, but also the synchronous transmission of information. If the subscriber uses the meter readings to pay for the consumed thermal energy and does so when it is convenient, even partially use the actual load of the systems is not possible.

Another way to estimate the energy consumed is to recalculate the calculated loads on the current conditions by the formula:

$$
Q_{H V}=24 \frac{t_{i}-t_{o}}{t_{i}-t_{O}^{c}} \sum_{j=1}^{k_{1}} Q_{H V_{j}}^{c}
$$


Where $\sum_{j=1}^{k_{1}} Q_{H V_{j}}^{c}, \mathrm{Gcal} / \mathrm{h},-$ total calculated load of heating and ventilation;

$t_{O}^{c},{ }^{\circ} \mathrm{C}$ - calculated outdoor temperature taken according to [12] equal to $-39{ }^{\circ} \mathrm{C}$;

$t_{o},{ }^{\circ} \mathrm{C}$ - current outdoor temperature;

$t_{i},{ }^{\circ} \mathrm{C}$ - calculated internal air temperature taken as $20^{\circ} \mathrm{C}$.

Assuming that the thermal load on the hot water systems is constant throughout the year, the thermal energy consumed is determined by the formula:

$$
Q_{H W}=24 \sum_{j=1}^{k_{2}} Q_{H W_{j}}^{c}
$$

Where $\sum_{j=1}^{k_{2}} Q_{H W_{j}}^{c}$, Gcal/day, - total calculated load for needs hot water systems.

Heat losses through thermal insulation were recalculated to the current conditions - the temperature of the outside air, the temperature of the coolant in the supply and return pipelines according to the formulas [13]:

- for sections of underground strip (ducted and ductless) total for supply and return pipelines $Q_{u}^{m}, \mathrm{Gkal} / \mathrm{day}$, according to the formula:

$$
Q_{u}^{m}=24 \cdot Q_{u}^{y} \frac{t_{s}^{m}+t_{r}^{m}-2 t_{\text {soil }}^{m}}{t_{s}^{y}+t_{r}^{y}-2 t_{\text {soil }}^{y}} \cdot 10^{-6}
$$

- for sections of the above-ground (above-ground and basement) laying separately on the giving $Q_{a . s}^{m}$ and $Q_{a . r}^{m}$ reverse, Gkal/day, pipeline formula:

$$
\begin{gathered}
Q_{a . s}^{m}=24 \cdot Q_{a . s}^{y} \frac{t_{s}^{m}+t_{0}^{m}}{t_{s}^{y}+t_{0}^{y}} \cdot 10^{-3}, \\
Q_{a . r}^{m}=24 \cdot Q_{a . r}^{y} \frac{t_{r}^{m}+t_{0}^{m}}{t_{r}^{y}+t_{0}^{y}} \cdot 10^{-3},
\end{gathered}
$$

Where $t_{S}^{m}$ и $t_{o}^{m},{ }^{\circ} \mathrm{C}$, - the average monthly temperature of the coolant in the supply and return pipelines of the heating network, respectively, obtained during the survey period;

$t_{\text {soil }}^{m}$ и $t_{O}^{m},{ }^{\circ} \mathrm{C}$, - average for the month value, respectively, of the soil on the depth of laying the pipes and outside air received during the survey period. For basement laying the temperature of internal air was taken equal to $20{ }^{\circ} \mathrm{C}$. Ground temperature was taken according to the data of the reference book [12].

Operating hour heat loss during average conditions was determined for sections of underground strip total for supply and return piping $Q_{u}^{y}, \mathrm{kcal} / \mathrm{h}$, by the formula:

$$
Q_{u}^{y}=\sum q_{u} K_{u} L \beta
$$

plots for ground installation separately for $Q_{a . s}^{y}$ and inverse $Q_{a . r}^{y}$, kcal / h, piping formulas:

$$
Q_{a . s}^{y}=\sum q_{a . s} K_{a . s} L \beta,
$$




$$
Q_{a . r}^{y}=\sum q_{a . r} K_{a . r} L \beta,
$$

$q_{\text {и }}, q_{a . s}$ и $q_{a . r}, \mathrm{kcal} /(\mathrm{m} \mathrm{h})$ - specific hourly heat losses, defined according to the norms of heat losses in accordance with the design standards of thermal insulation for piping and equipment for each diameter pipeline with an annual average conditions of operation of the heat network, for underground strip total for supply and return piping and separately for ground installation;

$\mathrm{L}, \mathrm{m}$, - length of pipelines on a site of a thermal network with diameter $\mathrm{d}$ in two-pipe calculation at under-ground laying and on the giving (return) line at overground laying;

$\beta$ - coefficient of local heat losses, taking into account the thermal losses of valves, compensators, supports; adopted for underground channel and aboveground gaskets equal to 1.2 with diameters of pipelines up to $150 \mathrm{~mm}$ and 1.15 with diameters of $150 \mathrm{~mm}$ and more, as well as with all diameters of the channel-free gaskets.

Analysis of the calculated load raises doubts about their absolute reliability. The calculated load on the DHW corresponds to the maximum load, rarely achievable in reality. Therefore, to use the contractual loads as calculated to estimate the actual consumption for heating, ventilation and hot water, the coefficients $\mathrm{m} 1, \mathrm{~m} 2, \mathrm{~m} 3$ were introduced into equation (1), after which the equation took the form:

$$
Q=m_{1} \cdot Q_{H V}+m_{2} \cdot Q_{H W}+m_{3} \cdot Q_{H L}
$$

To obtain the coefficients $\mathrm{m} 1, \mathrm{~m} 2, \mathrm{~m} 3$ it is necessary to use the least squares method [14]. The initial data are:

- telemetry data - average monthly values of ambient air temperature and the coolant supply and return lines, the values of the costs in the supply and return lines;

- contractual (settlement) load for heating and ventilation, calculated on the actual average conditions;

- heat losses converted to actual average monthly conditions.

The adequacy of the mathematical model to the real process was checked for all days included in the sample. The deviation of the predicted values from the actual values was estimated by the formula:

$$
\varepsilon=\frac{\hat{Q}-Q}{Q} \cdot 100 \%
$$

where $Q, \mathrm{Gcal} / \mathrm{day}$, - predicted value of thermal energy consumption;

$\mathrm{Q}, \mathrm{Gcal} /$ day, - actual heat release.

The mathematical model of material balance of the heat carrier is in direct dependence on mathematical model of balance of thermal energy, i.e. the coefficients $m_{1}, m_{2}$ received for model of thermal balance have to be fair at reduction of balance of the heat carrier.

The consumption of make-up water is equal to the amount of coolant consumption for the needs of hot water supply of subscribers with an open circuit connection and leaks:

$$
G=G_{H W}+G_{W L} \text {. }
$$

Since leakage is a small proportion of the consumption of hot water, it is not taken into account in future consideration.

Daily consumption of coolant for needs of hot water supply is determined by the formula:

$$
G_{H W}=24 \cdot Q_{H W}^{c} \cdot \frac{\rho_{H W}}{t_{s}^{a}-t_{c}^{a}},
$$


where $Q_{H W}^{c}, \mathrm{Gcal} / \mathrm{h}$, - the estimated load for needs of hot water supply;

$t_{s}^{a},{ }^{\circ} \mathrm{C}-$ actual temperature in the supply line;

$t_{c}^{a},{ }^{\circ} \mathrm{C}$ - actual temperature of the cold water;

${ }^{r} H W$, кг/м3 - the density of the coolant at a temperature ${ }^{t} s$

The total flow rate in the supply lines $G_{S S}$ is equal to the amount of coolant costs for heating and ventilation needs and hot water needs of subscribers:

$$
G_{S \sum}=m_{1} G_{H V}+m_{2} G_{H W}
$$

where $G_{H V}, \mathrm{t} / \mathrm{day}$, - consumption for heating and ventilation, determined by the formula:

$$
G_{H V}=\frac{24 \cdot 1000 \cdot Q_{H V}^{c}}{t_{s}^{c}-t_{r}^{c}},
$$

$Q_{H W}^{c}, \mathrm{Gcal} / \mathrm{h}$, - calculated thermal load for heating and ventilation;

$t_{S}^{c}, t_{r}^{c},{ }^{\circ} \mathrm{C},-$ the temperature of the coolant, respectively, in the supply and return pipelines, determined by the temperature schedule and equal to 130 and $70{ }^{\circ} \mathrm{C}$;

$G_{H W}, \mathrm{t} /$ day, - determined by the formula (14);

$\mathrm{m}_{1}, \mathrm{~m}_{2}$ - linear regression coefficients (11).

The adequacy of the model to the actual data can be checked only for the heating period, since the coolant consumption for heating and ventilation is 0 in the summer. The criterion is the deviation of the amount of coolant costs for heating, ventilation and hot water from the amount of measured costs in the supply lines:

$$
\varepsilon_{G}=\frac{m_{1} G_{H V}+m_{2} G_{H W}-G_{S} \sum}{G_{s \Sigma}} \cdot 100 \%,
$$

\section{Research object}

The heat and mass balance were made for the real heat network. The way of regulation is qualitative. Wiring diagram for domestic hot water - open.

The source has 3 mains, in the summer period only 2 of them more often work. The periodicity of the data collection is a day. The data of telemetry include period of 629 days. Information about actual consumption of thermal energy is practically absent. It did not make sense to judge the consumption of thermal energy by payments for it, since the analysis of payments showed the absence of the system both in the payment periods and in the methods of calculation. Only heating network was connected to 899 subscribers.

The system of pipelines consisted of 1295 sections of different diameters, methods and years of laying. 


\section{Results}

When compiling the heat balance, it is important to use daily telemetry data at the source. The outdoor temperature was presented both actual and predicted. The samples of each of them did not fully cover all 629 days, while there was a time period when both temperatures were present. The frequency distribution shows that the difference between the predicted and actual temperatures is described by the normal distribution with the parameters $m=0.0, \sigma=1.4$ (Fig.1), and in the absence of the actual temperature can use the predicted.

The accumulation of data makes it possible to assess climate change (Fig.2). Temperature fluctuations during the month make it difficult to assess the nature of the changes (Fig.2), averaging of daily temperatures during the month allows to compare them with reference data [12]. The average monthly average actual data is the same as the reference data. For example, cold February 2014 is compensated by warm March and April.

Analysis of the temperature in the supply and return pipeline at the source (Fig.4) makes it possible to estimate deviations from the accepted temperature schedule. The temperature of the mains water is too high in summer (Fig.5), in the heating period at low outside temperatures, the coolant temperature is lower than required by the schedule

To analyze the data, it is not enough to visualize them on the charts, the use of statistical methods allows to quantify the results. For example, the statistical analysis presented in the table. 1, showed that it is possible to accept the hypothesis of the constancy of the daily total flow rate in all supply lines only for heating periods 2013-2014 (sample 1) and 20142015 (sample 3).

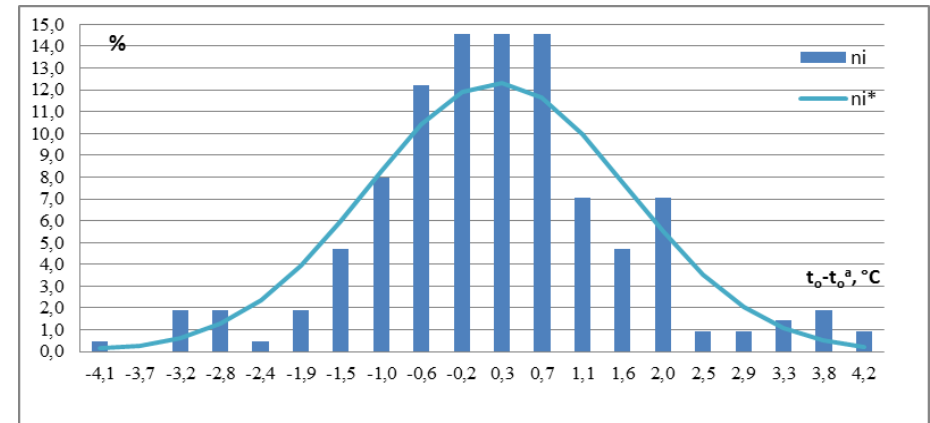

Fig. 1 Frequency response of the difference between predicted and actual outdoor temperatures

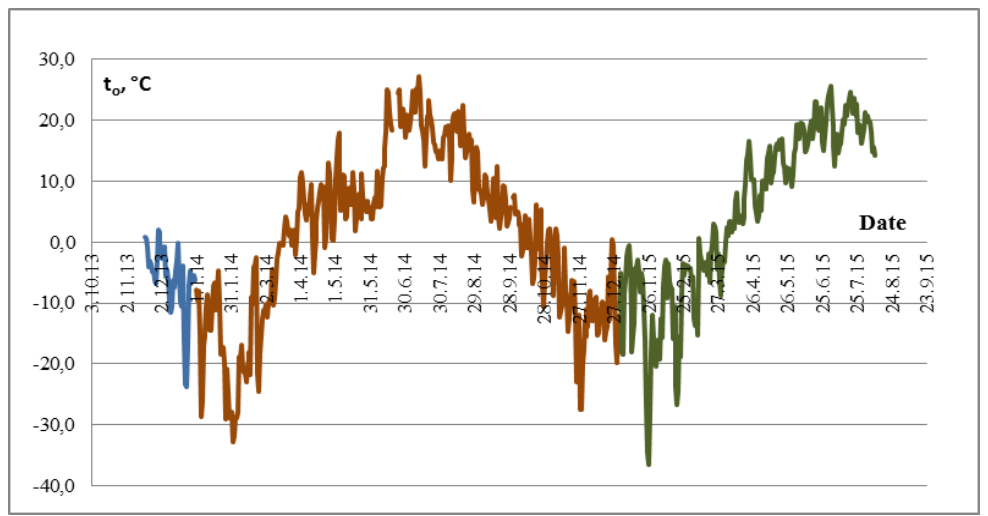

Fig.2 Changes in the average daily outdoor temperature 


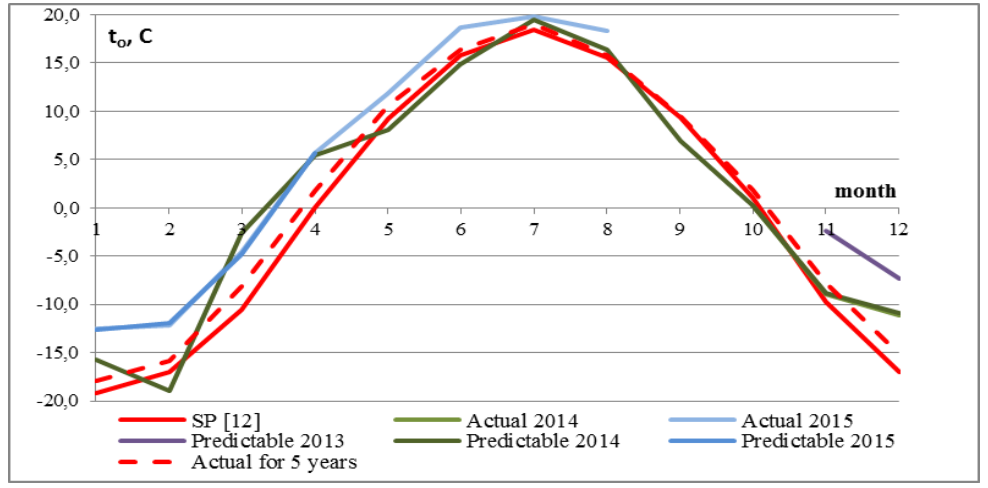

Fig. 3 Change in average monthly outdoor temperature

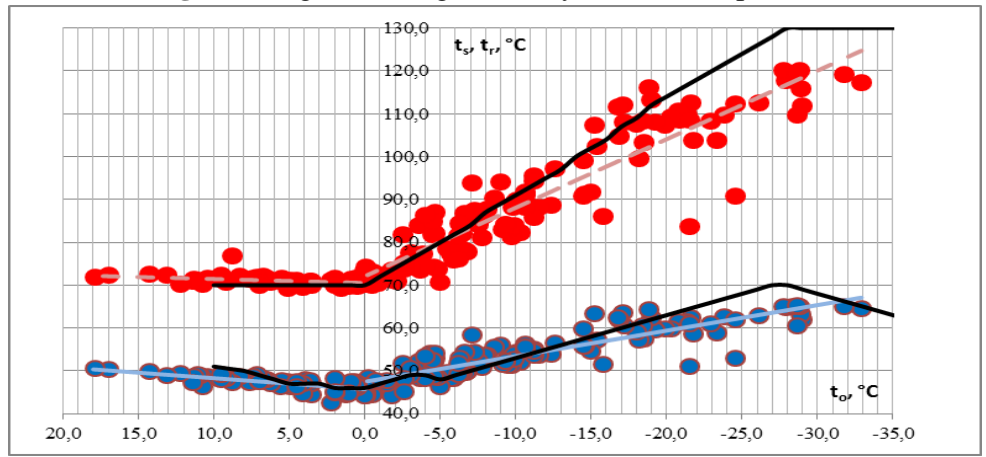

Fig. 4 Change of coolant temperature in the supply and return pipeline during the heating period

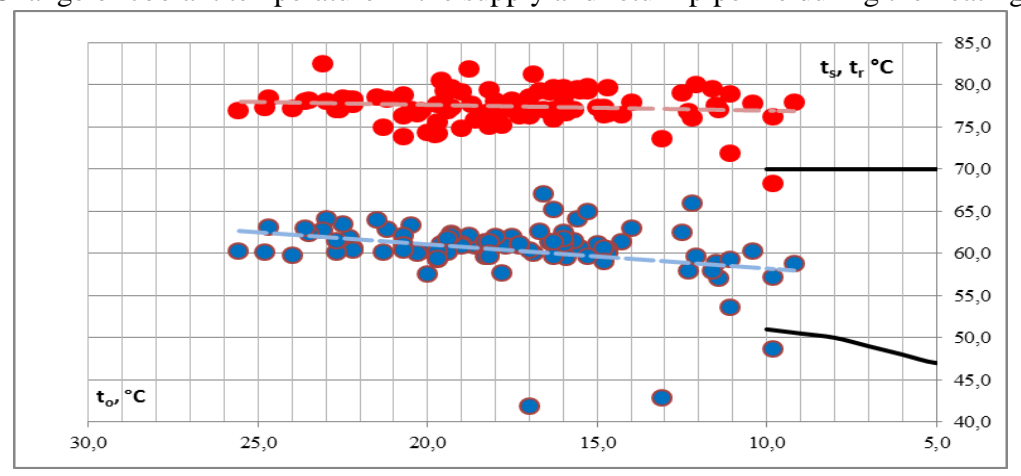

Fig. 5 Change of coolant temperature in the supply and return pipeline in summer

Table 1. Testing the hypothesis of the constancy of the average daily total costs in the supply lines, regardless of the season

\begin{tabular}{|c|c|c|c|c|c|c|c|c|c|c|c|}
\hline \multicolumn{2}{|c|}{$\begin{array}{c}\text { №№ } \\
\text { compared } \\
\text { samples }\end{array}$} & \multirow[t]{2}{*}{$\begin{array}{l}\bar{G}_{S_{\mathrm{S}} i} \\
\mathrm{t} / \text { day }\end{array}$} & \multirow[t]{2}{*}{$\begin{array}{c}S_{i} \\
t / d a y\end{array}$} & \multirow[t]{2}{*}{$\begin{array}{c}\text { Sample } \\
\text { size } \\
n_{i}\end{array}$} & \multirow[t]{2}{*}{$\begin{array}{l}\bar{G}_{s_{\mathrm{S}} j} \\
\text { t/day }\end{array}$} & \multirow[t]{2}{*}{$\begin{array}{c}s_{j} \\
t / d a y\end{array}$} & \multirow[t]{2}{*}{$\begin{array}{c}\text { Sample } \\
\text { size } \\
n_{j}\end{array}$} & \multirow[t]{2}{*}{$\begin{array}{c}\left|\bar{G}_{s_{s} i}-\bar{G}_{s_{s} j}\right| \\
\text { t/day }\end{array}$} & \multirow[t]{2}{*}{$\Rightarrow$} & \multirow{2}{*}{$t^{\prime} \sqrt{\frac{s_{i}^{2}}{n_{i}}+\frac{s_{j}^{2}}{n_{j}}}$} & \multirow{2}{*}{$\begin{array}{c}\text { The average values } \\
\text { are equal to each } \\
\text { other }(+) / \text { not equal } \\
(-)\end{array}$} \\
\hline $\mathrm{i}$ & $j$ & & & & & & & & & & \\
\hline 1 & 2 & 72251 & 1452 & 150 & 5659 & 289 & 77 & 66592 & 171 & 243 & - \\
\hline 1 & 3 & 72251 & 1452 & 150 & 72322 & 1724 & 190 & 71 & 339 & 339 & + \\
\hline 1 & 4 & 72251 & 1452 & 150 & 16042 & 782 & 65 & 56209 & 206 & 302 & - \\
\hline 2 & 3 & 5659 & 289 & 77 & 72322 & 1724 & 190 & 66663 & 214 & 255 & - \\
\hline 2 & 4 & 5659 & 289 & 77 & 16042 & 782 & 65 & 10383 & 79 & 204 & - \\
\hline 3 & 4 & 72322 & 1724 & 190 & 16042 & 782 & 65 & 56280 & 237 & 312 & - \\
\hline
\end{tabular}


The results of the regression analysis are presented in the table. 2. Model 1 includes the 3 components of the balance sheet (11); model $2-2$ terms - heat loss of the piping to be equal to 0 ; model $3-3$ components, the coefficient of $m_{3}$ is initially equal to 1 .

Table 2. The results of the regression analysis

\begin{tabular}{|l|r|r|r|c|}
\hline \multirow{2}{*}{ №№ } & \multicolumn{3}{|c|}{ Coefficients } & \multirow{2}{*}{$\mathrm{r}^{2}$} \\
\cline { 2 - 4 } & $\mathrm{m}_{1}$ & $\mathrm{~m}_{2}$ & $\mathrm{~m}_{3}$ & \\
\hline 1 & 1,268 & 0,319 & 0,021 & 0,996 \\
2 & 1,270 & 0,320 & 0 & 0,996 \\
3 & 1,170 & 0,260 & 1 & 0,995 \\
\hline
\end{tabular}

When removing heat losses from the components of the balance factors $\mathrm{m}_{1}$ and $\mathrm{m}_{2}$ changed to thousandths of a share (compare the first and second lines of the table. 2). At $100 \%$ taking into account heat losses $\left(\mathrm{m}_{3}=1\right)$, the factors $\mathrm{m}_{1}$ and $\mathrm{m}_{2}$ changed more significantly, respectively, by $7 \%$ and $18 \%$.

In all three models, the deterministic coefficient $r^{2}$ is close to 1 , indicating no difference between actual and estimated values.

The actual and predicted values of heat output to the network are shown in Fig. 6. Repeating the numbers of the months is the month of transition from the heating mode to summer and back Values $\varepsilon$ calculated according to the formula (12), is the same for models 2 and 3. The greatest error have days, which coincide with the period of transition from the heating period to the summer and back. During the summer period, periods of 8 days are allocated, which are characterized by significant deviations of the predicted values from the actual ones. This is due to the change in the mode of operation of the heat network (preventive maintenance and disconnection of consumers). Average $\varepsilon$ values are $-3.8 \%$ for model 2 and $-5.5 \%$ for model 3 .

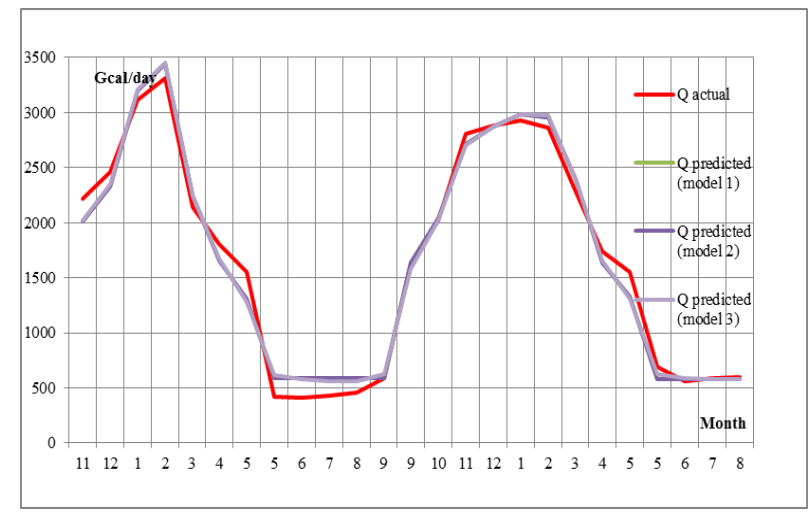

Fig. 6. Comparison of actual and predicted values $Q$

The ratio of the coolant flow $G_{H W}$ calculated by the formula (14) to the actual makeup consumption $\mathrm{G}$ was analyzed separately for each season. Table 3 shows the average ratio, standard deviation, and confidence intervals. 
Table 3. Statistical characteristics of the ratio of coolant flow to make-up flow

\begin{tabular}{|l|l|l|l|l|l|}
\hline №№ & Sample & $\begin{array}{l}\text { Average } \\
\mathrm{G}_{\mathrm{HW}} / \mathrm{G}\end{array}$ & Standard deviation & \multicolumn{2}{l|}{ Confidence interval } \\
\hline 1 & 1 & 0,25 & 0,05 & 0,16 & 0,34 \\
\hline 2 & 2 & 0,19 & 0,05 & 0,09 & 0,28 \\
\hline 3 & 3 & 0,22 & 0,03 & 0,16 & 0,29 \\
\hline 4 & 4 & 0,18 & 0,04 & 0,09 & 0,26 \\
\hline
\end{tabular}

The coefficients $\mathrm{m} 1$ and $\mathrm{m} 2$ obtained for the approximating dependence (11) were used to predict the total flow rate in the supply lines according to the formula (15). The prediction error was estimated using the parameter || $\mathrm{G}$. . The Results presented in the table.4, indicate the validity of the use of model 3 coefficients. The mean value of ||$G$. is $-0.7 \%$ for sample 1 and $1.4 \%$ for sample 3 .

Table 4. Error estimation

\begin{tabular}{|c|c|c|c|c|c|c|}
\hline №№ & Model & Sample & $\begin{array}{c}\text { Average } \\
\varepsilon_{\mathrm{G}}\end{array}$ & Standard deviation & \multicolumn{2}{|c|}{ Confidence interval } \\
\hline 1 & 2 & \multirow{2}{*}{1} & 9,0 & 18 & 25,6 & 43,7 \\
\cline { 1 - 5 } 2 & 3 & & $-0,7$ & 16 & $-32,2$ & 30,8 \\
\hline 3 & 2 & \multirow{2}{*}{3} & 11,3 & 6,2 & $-0,7$ & 23,4 \\
\hline 4 & 3 & & 1,4 & 5,5 & $-9,4$ & 12,2 \\
\cline { 4 - 6 } & & &
\end{tabular}

\section{Discussion}

Coefficients, which are included in a equation of the thermal balance, can be explained in the following way. The value of the coefficient $m_{1}>1$ indicates either incomplete information about the load on heating and ventilation, or about the over expenditure of thermal energy. The value of $m_{2}<1$ coefficient can be interpreted as the coefficient of nonuniformity of heat energy consumption for domestic hot water needs. These values are valid for the network in question. When receiving new telemetry data, changing operating modes and connected load coefficients included in the equation must be recalculated.

Mathematical model (11) permits to predict amount of thermal energy, which is necessary for providing loads on heating, ventilation and hot water, depending on the projected outdoor temperature.

\section{Conclusions}

1. Turning into the level Smart Grid is not only a networks and equips fitting out by devices of the automation and telemechanics, but at the same time development of algorithms and programs for information processing.

2. One the problem facing the heat supply company is a preparation of thermal balance. The standard approach assumes that all the residual balance attributed to heat losses. This leads to a rise in the cost of thermal energy and, as a consequence, to an increase in utility bills. Using the available evidence, the proposed method allows to estimate the share of each term in the heat balance.

3. Analysis of telemetry data should be carried out by considering each individual measurement and the entire sample. The use of statistical methods is the first step in increasing the intellectual level in the operation of engineering systems. 


\section{References}

1. SP 41-101-95 Design of heat points

2. M.A. Kolchina, A. Fenselb, D.I. Mouromtseva, S.O. Popova, D.S. Pavlova, N.V. Klimova, A.A. Andreeva, D.S. Garayzueva Scien. and tech. j. of infor., mech. and opt. 15 (2015)

3. N.I. Povorozniuk, K.E. Bo-brivnyk Her. of the Nat. Tech. Univ. "KhPI". 62 (968), 162-168 (2012)

4. Esri - GIS Mapping Software, Solutions, Services, Map Apps and Data. - URL: http://www.esri.com/

5. K. Moslehi, R. Paper 10SG0068, IEEE PES Conference on "Innovative Smart Grid Technologies" (2010)

6. Ren J., M. Kezunovic IEEE Transactions on Power Delivery 26,1392-1402 (2011)

7. Z. Chen, F. Li, L. Fan, P. Proceedings of the 8th WSEAS International Conference on ELECTRIC POWER SYSTEMS, HIGH VOLTAGES, ELECTRIC MACHINES (POWER '08) 212-217(2008)

8. Grid 2030: A National Version for Electricity's Second 100 Years. - Office of Electric Transmission and Distribution United State Department of Energy, July 2003. - 45 p.

9. European Smart Grids Technology Platform: Vision and Strategy for Europe's Electricity Networks of the Future. - Euro-pean Commission, 2006. - $44 \mathrm{p}$.

10. Strategic Deployment Document for Europe Electricity Networks of the Future European Technology Platform, European Commission, April 2010. - 54 p.

11. N.N. Novitsky, Z.I. Shalaginova, E.A. Mikhailovsky Proceedings of ISTU Vol. 21, No. 9(2017)

12. SP 131.13330.12 Building climatology Aktualizirovannaya redaktsiya SNiP 23-01-99*

13. SP 61.13330.2012 Designing of thermal insulation of equipment and pipe lines Aktualizirovannaya redaktsiya SNiP 41-03-2003

14. David M. Himmelblau Process analysis by statistical methods (Moscow, Mir, 1973). 